\title{
SINFONÍA ERÓTICA EN EL PASADO DE ALAN PAULS*
}

\author{
EROTIC SYMPHONY IN ALAN PAUL'S EL PASADO
}

\author{
Alexis Candia-Cáceres \\ Universidad de Playa Ancha. Valparaíso, Chile. \\ ivan.candia@upla.cl
}

\begin{abstract}
Resumen: Este artículo propone una revisión de la función del erotismo en El pasado de Alan Pauls. Para esto se realiza una interpretación del fenómeno erótico en la novela a partir de la noción de "sinfonía erótica", concepto que plantea la presencia de cuatro movimientos de representación y construcción de la voluptuosidad, los que están vinculados, directamente, con las cuatro mujeres que se relacionan con Rímini: Sofía, Vera, Carmen y Nancy.
\end{abstract}

Palabras clave: Voluptuosidad, narrativa argentina, siglo XX.

Abstract: This article proposes a revision of the role of eroticism in Alan Paul's $E l$
pasado. The study focuses on the notion of "erotic symphony" as a way to interpret
the erotic phenomenon in the novel. The concept determines the presence of four mo-
vements in the construction and representation of voluptuousness, which are directly
related to the four women that swirl around Rímini: Sofía, Vera, Carmen, and Nancy.

Keywords: Voluptuousness, Argentine narrative, Twentieth Century.

Recibido: 03.03.2015 Aceptado: 27.04.2015.

L PASADO (2003) de Alan Pauls explora no solo un amor, protagoniza-
arranca desde el pasado, se extiende por el presente y se proyecta hacia el

* Proyecto Postdoctorado $2012 \mathrm{~N}^{\circ} 3120104$ "Las mil formas de Venus en la narrativa hispanoamericana contemporánea", financiado por el Fondo Nacional de Ciencia y Tecnología, Fondecyt. Investigador Responsable: Iván Alexis Candia Cáceres. 
futuro hasta construir una verdadera "geología del amor". También, plasma una "sinfonía erótica" que penetra por las hendeduras de la novela, envuelve a los personajes y termina tocando numerosos ritmos -matizados por diferentes instrumentos y tonalidades- que generan una amplia representación del eros en la historia de Sofía, Vera, Carmen, Nancy y Rímini. La indagación del fenómeno erótico es una constante del relato del escritor argentino. De esta forma, Alan Pauls es capaz de representar desde tenues llamaradas hasta penetrantes igniciones en las relaciones que Rímini establece con las mujeres que se involucran en su vida. Pauls plantea, en este sentido, una relación erótico-sentimental que resulta inversamente proporcional: entre mayor sea la conexión amorosa entre los amantes menor será la intensidad erótica y, en oposición, entre menor sea el vínculo sentimental entre los amantes mayor será la voluptuosidad que involucra la escenificación del encuentro carnal.

No es azaroso el título de este artículo. La sinfonía es una composición musical construida para ser ejecutada por una orquesta que se caracteriza por estar dividida en cuatro movimientos, cada uno de los cuales tiene un tiempo y una estructura distinta. Alan Pauls replica la estructura de la sinfonía en El pasado debido a que construye la novela sobre la base de cuatro movimientos delimitados por los vínculos erótico-sentimentales que Rímini establece con las mujeres que juegan un rol central en su experiencia vital: Sofía, Vera, Carmen y Nancy. Las relaciones de Rímini con ellas son tratadas con variados e intensos matices por Pauls, lo que enriquece el modo de representación y simbolización del erotismo en El pasado.

El tratamiento del fenómeno erótico-amoroso en la novela ha sido abordado, someramente, por la crítica literaria. Elena Donato destaca cómo $E l$ pasado puede ser leída a partir de la traducción del sentir amoroso: "Así, la novela de Pauls es un tratado de la pasión amorosa, sólo a condición de que se entienda el amor como un problema de traducción" (2005: 5). En esta misma dirección, se puede incluir la reseña "Gordura" que Ignacio Echevarría publicó originalmente en el suplemento Babelia del diario español El País. Para Echevarría, El pasado es tanto una historia de amor como de horror. Echevarría establece que la novela aborda las posteridades del amor, sus tiranías, "[...] de quienes militan en él como en una religión, de su tendencia a constituirse en destino y doblegar el tiempo en una suerte de 'oceánica continuidad sentimental”' (2007: 135). Rodrigo Fresán plantea, 
a su vez, que "El pasado es la más grande y terrible historia de amor jamás contada" (cit. en Aliaga, 2006: 9). Alejandro Aliaga realiza, por último, un análisis de El pasado a partir del cruce de la teoría del amor y del arte, proponiendo que ambos son organismos enfermos en permanente mutación. En el artículo“La geología siniestra del amor en El pasado de Alan Pauls” propongo, en tanto, estudiar la presencia del amor en la novela a partir de nociones que, en mi perspectiva, resultan claves para comprender el noviazgo de la pareja protagonista en el texto: el "amor siniestro" y "geología del amor".

Alan Pauls da forma a una "sinfonía erótica" donde la construcción de cuatro movimientos sensuales genera disímiles intensidades y significados y, sobre todo, donde la representación del eros adquiere un cariz distinto, marcado, sobre todo, por el tipo de representación de cada una de las relaciones erótico-amorosas. Pauls le confiere especial interés a la variada y rica utilización del lenguaje a la hora de reconstruir las conexiones sexuales entre Rímini y las distintas mujeres con las que comparte fragmentos de su vida.

\section{Cuatro mujeres}

Invierno. El pasado relata el "amor geológico" que se produce en una pareja de amantes argentinos. Alan Pauls construye la compleja y extensa historia de amor de Sofía y Rímini, historia que se proyecta por más de una década en la que ambos intentan alcanzar la perfección del amor: "Era simple: no sentían que tuvieran que ser leales a los amigos, ni siquiera a sus sentimientos; debían toda su lealtad a la situación, a los ideales de la situación: amor, confianza, intimidad, respeto, profundidad -esas perfecciones por las que estaban dispuestos a sufrir, a romper lanzas, a sacrificarlo todo" (2003: 49). El pasado intenta destacar el trayecto ejemplar del amor de Rímini y Sofía, quienes experimentan las múltiples posibilidades de sentir amoroso. El relato de los primeros doce años de pasión manifiesta el carácter del vínculo erótico-sentimental de la pareja:

Lo habían hecho todo. Se habían desflorado y raptado de sus respectivas familias; habían vivido y viajado juntos; juntos habían sobrevivido a la 
adolescencia y luego a la juventud y asomado la cabeza a la vida adulta; juntos habían sido padres y llorado al muerto diminuto que nunca llegaron a ver; juntos habían conocido maestros, amigos, idiomas, trabajos, placeres, lugares de veraneo, decepciones, costumbres, platos raros, enfermedades -todas las atracciones que podía ofrecerles una versión prudente pero versátil de esa mezcla de sorpresa y fugacidad que se llama normalmente vida [...] Y para que la colección estuviera completa, completa definitivamente, ellos mismos agregaron la pieza cumbre: la separación. [...] La separación no era el más allá del amor: era su límite, su colmo, el borde interno de su confín: si se consumaba como ellos proponían consumarla, amorosamente, era lo que le permitiría morir bien (Pauls, 2003: 59).

A pesar de la meticulosa planificación del desenlace del romance, Sofía no tarda en darse cuenta de que la ruptura constituye un error y que Rímini representa, en términos de Breton, su única posibilidad de consolidar un amor único. El siguiente extracto de una carta de Sofía es concluyente en este sentido:

Venimos de tan lejos, Rímini. Tenemos millones de años. El nuestro es un amor geológico. Las separaciones, los encuentros, las peleas, todo lo que pasa y lo que se ve, lo que tiene fecha, 1976, todo eso tiene tanto sentido como una baldosa quebrada comparada con el temblor que lleva milenios haciendo vibrar el centro de la tierra (2003: 507, cursivas de Pauls).

No sucede lo mismo con Rímini quien realiza un largo periplo -que incluye varias amantes- a fin de consolidar la estrategia de olvido que implementa para librarse de Sofía. Durante la extensa separación, sin embargo, Sofía acecha de manera permanente a su antiguo amante. En "La geología siniestra del amor en El pasado de Alan Pauls" establezco cómo el "amor siniestro" define la manera de relacionarse de Sofía con Rímini tras el quiebre de la relación amorosa:

La pasión de Sofía puede ser leída no solo como un himno a la entrega total sino como un amor desenfrenado que termina por socavar las bases de la nueva vida de Rímini. Más aun cuando ésta invade de manera espectral el espacio de su antiguo amante para arruinarle, una y otra vez, las posibilidades de generar una historia distinta al pasado. Sofía es 
todo aquello que debía haber quedado oculto, secreto, reprimido, pero que se ha manifestado de manera espeluznante en la vida de Rímini. A veces de manera accidental, a veces de forma voluntaria, Sofía desencadena una serie de catástrofes que acaban por imponer lo que Kristeva denomina como un "amor loco" (Candia-Cáceres, 2014: 61-62).

Tras años de disputas y desastres sentimentales, la aparición de Sofía en un momento de extrema necesidad en la vida de Rímini, allanará el camino para que el antiguo traductor acepte retornar al antiguo "museo sentimental” que había erigido junto a Sofía. Así, se cumple la máxima mencionada, originalmente, por Pierre-Gilles, luego ratificada por Sofía y que, por cierto, es una alusión a Torrentes de amor de John Cassavetes: "El amor es un torrente continuo" (Pauls, 2003: 131). De esta forma, es factible comprender la construcción del amor en la novela:

La "geología del amor" consiste en una pasión que se extiende por varios años e incluso décadas y que tiene una compleja y vasta historia. $\mathrm{Al}$ igual como sucede con el objeto de estudio de la geología, la Tierra, el amor de Rímini y Sofía se despliega hacia el pasado y se proyecta hacia el futuro, erigiéndose, en definitiva, como una historia sin fin o al menos como una historia que no tiene señales de un término siquiera distante (Candia-Cáceres, 2014: 52).

Pauls se hace cargo de un extenso vínculo sentimental que llega a ejecutar la "totalidad" del amor. Bajo esta perspectiva, parafraseando una idea propuesta por Cedomil Goic, es posible sostener que El pasado es una "nueva novela total" de temática amorosa. Si las "nuevas novelas totales" tienen que ver con la construcción de mundos autónomos, generados por autores que se erigen como "[...] creadores de mundos abigarrados que retienen en su propia red, que juegan con numerosas referencias cruzadas, que describen estratos diferentes de un mundo nada simple, y que iluminan sectores diversos de una realidad social y culturalmente múltiple" (Goic, 2000: 119); es dable sostener que Pauls intenta aproximarse de manera abarcadora al fenómeno amoroso, explorando las numerosas paradojas del amor y del desamor en la Argentina finisecular.

En esa línea, es claro que la relación amorosa experimenta diferentes vaivenes que deberían arrojar disímiles intensidades a la hora de cristalizar el sentir erótico. Curiosamente, el único punto donde existe cierta pasión 
entre ambos es cuando enfrentan la primera separación, período en el que en condición de amantes gozan de un placer intenso:

Los encuentros, signados por esa extraña forma de amoralidad que supone engañar a una amante de días con una esposa de años, desembocaban en largos certámenes confesionales (Rímini por fin lloraba) o en sesiones de amor volcánicas que aprovechaban para enseñarse los trucos que habían aprendido lejos del otro (Pauls, 2003: 57).

$\mathrm{Al}$ margen de ese ardiente oasis, la exploración erótica de la pareja es, por decir lo menos, fría. Al enfrentarse a la simbiosis sentimental de Rímini y Sofía, Pauls opta por una representación aséptica de la ritualización erótica, liberándolos de la pasión y del desenfreno sexual, tal como se puede apreciar en una de las pocas ocasiones en que levanta sus sábanas:

Hicieron el amor casi dormidos, sin despegarse, frotándose con una ebria indolencia. Rímini ni siquiera estaba seguro de haberla penetrado. Acabó rápido, más rápido que ella, en todo caso, y mientras lo sacudían las convulsiones tuvo la certeza, inexplicable, pero muy convincente, de que esa ración de semen que expulsaba a ciegas, sin saber muy bien dónde, era la última (Pauls, 2003: 547).

Pauls intenta situarlos más allá de los limitados deseos de la carne: "No había roturas. Nada se había marchitado. Pasaban largas temporadas sin hacer el amor, es cierto, pero ni siquiera entonces la palabra "deterioro" parecía oportuna: el sexo nunca había tenido una importancia especial para ellos" (Pauls, 2003: 58). Bajo esta perspectiva, Pauls parece construir una historia platónica más que un amor de carne y sangre.

La lectura del erotismo efectuada por Byung-Chul Han es útil para leer el enfriamiento del amorío de Sofía y Rímini, específicamente porque aborda los efectos del "amor imposible". Cabe recordar, en este sentido, que los amantes argentinos asumen que su amor es “[...] una obra de arte" (Pauls, 2003: 58) y que, en consecuencia, demanda la perfección. Alan Pauls complementa esta apreciación sobre Rímini y Sofía:

Sofía y Rímini se separan porque la relación amorosa que los une, llega a una perfección de obra de arte. Y las obras de arte son geniales para contemplar pero nadie puede vivir dentro de una. Es un poco lo mismo 
que pasa con las especies que llegan a un estado evolutivo de perfección y después no pueden si no extinguirse (Encuentros digitales, 2004).

En efecto, no es posible sustentar un noviazgo que aspira a perpetuarse en un museo, debido a que se erige, finalmente, como un amor imposible. De allí que sea útil la reflexión de Byung-Chul Han en La agonía del Eros en orden a que "[...] el amor imposible conduce a la depresión” (Han, 2014: 13). Para Han solamente el eros es capaz de vencer el ensimismamiento propio de la época contemporánea y, en este sentido, es capaz de situarse más allá de las exigencias del capitalismo contemporáneo, es decir, de elevados niveles de rendimiento y sumisión al poder: "El Eros, el deseo erótico, vence a la depresión. Conduce del infierno de lo igual a la atopía; es más, a la utopía de lo completamente otro" (Han, 2014: 17). El enfriamiento de la pasión de los protagonistas de El pasado deriva de la voluntad de construir un amor idealizado que, progresivamente, los separa del deseo de penetrar y de gozar del otro.

El pasado pone en entredicho, entonces, la teoría del amor y del erotismo formulada por Octavio Paz en La llama doble, debido a que el amor de Sofía y Rímini está lejos de sustentarse en el fulgor erótico: "El fuego original y primordial, la sexualidad, levanta la llama roja del erotismo y ésta, a su vez, sostiene y alza otra llama, azul y trémula: la del amor. Erotismo y amor: la llama doble de la vida" (Paz, 1994: 7). Paz construye una teoría piramidal en la que la sexualidad sustenta al erotismo y éste, a su vez, sostiene al amor. De ahí que en La llama doble Paz sostenga que: "No hay amor sin erotismo como no hay erotismo sin sexualidad. Pero la cadena se rompe en sentido inverso: amor sin erotismo no es amor y erotismo sin sexo es impensable e imposible” (1994: 106). Sin embargo, la relación amorosa de Sofía y Rímini tiene que ver con la comunión espiritual y no con el goce carnal. Así, la historia de amor de El pasado deconstruye la propuesta de Paz. Si bien el amor se vio acrecentado, en un primer momento, por el deseo erótico, el trayecto de la pareja deviene, prontamente, en un amor idílico. De hecho el propio Pauls califica a Sofía y Rímini como: “[...] dos amantes platónicos" (Encuentros digitales, 2004). De esta forma, el apego de Rímini y Sofía no se sostiene en la pasión sino que éste, más bien, prescinde, del placer erótico.

A partir de la relación de Sofía y Rímini es posible comenzar a ratificar 
la tendencia planteada en la introducción de este trabajo: entre más intensa es la presencia de la conexión sentimental menor es el placer erótico y viceversa. De allí que el erotismo que emerge de la conexión de Sofía y Rímini sea, en la mayor parte de la novela, gélido. No sucede lo mismo con las otras parejas de Rímini. Nancy, Vera y Carmen mantienen con el traductor argentino relaciones eróticas mucho más intensas pero que, a su vez, no alcanzan el compromiso sentimental que se da con Sofía. De hecho, las tres mujeres son parte del extenso paréntesis que implica su separación, separación que, en cualquier caso, se desvanece cuando ambos retoman su "amor geológico" y regresan al "museo sentimental" que construyeron durante sus doce años de noviazgo.

Primavera. Tras el término del noviazgo con Sofía, época marcada por la abrumadora estabilidad sentimental que logra forjar en doce años, Rímini opta por el olvido como estrategia de superación de la relación amorosa. El deseo de olvido de Rímini es, además, una estrategia válida para superar la permanente táctica de conquista de Sofía, es decir, su voluntad de inocular recuerdos en la mente de Rímini a través de, por ejemplo, la serie de cartas que le envía para "sembrarse". Sofía lee las intenciones de su ex pareja y el rol que juega su nueva amante, Vera, en la operación de amnesia montada por el traductor argentino.

Eso es avanzar, para vos. Cada borrón un paso adelante, ¿no? Y así te vas limpiando. Así te vas deshaciendo de lo que no te sirve. Para qué tanto lastre ¿no? Se junta polvo, se ocupa espacio, siempre hay que estar ordenando. Mejor sacárselo de encima. "Liberarse". Por eso te buscaste esa chica, ¿no? Es joven... no tiene pasado [...] Ideal. Atrás no hay nada. Ahora todo está adelante (Pauls, 2003: 176).

Rímini realiza un radical cambio de estilo de vida, inaugurado por la irrupción de Vera, una hermosa y celópata mujer que lo lleva a revitalizar un ardor erótico que se había apaciguado con Sofía. Vera es, en este sentido, una aparición fulminante con la que establece una rápida e intensa relación amorosa que lo lleva a gozar de los placeres carnales:

[...] se deslizaba debajo de las sábanas, le daba calor, se calzaban uno en el otro, las manos de ella entre las piernas de él, las manos de él en las 
axilas de ella, las piernas enredadas, $y$, sin hacer el menor esfuerzo, sin siquiera moverse, como si el deseo fuera tan intenso que ya no necesitaba órganos para manifestarse, cruzaban un umbral y se estremecían en millones de espasmos diminutos y caían en el sueño sin separarse (Pauls, 2003: 154).

No sólo se produce un incremento en la temperatura del vínculo amoroso sino que, también, la frecuencia del placer alcanza una dinámica superior. De hecho, el viaje que realizan juntos a Valeria del Mar evidencia una "beligerancia vital", al decir de Pauls, que irrumpe continuamente en las jornadas consagradas al eros junto a Vera:

Rímini nunca había sentido las piernas tan lánguidas como cuando abordó el ómnibus de vuelta. No eran solo las caminatas por la playa, ni los peloteos encarnizados en la terraza, ni los extraños, incómodos pero estimulantes desafíos gimnásticos que lo habían obligado a enfrentar un par de sesiones de amor a la intemperie. Era el cansancio de lo puro, lo liso, lo homogéneo de la felicidad (Pauls, 2003: 186).

Ahora bien, la llegada de Vera es acompañada por la sobre-estimulación que el traductor argentino experimenta en su vida diaria. La desatada sensibilidad de Rímini se manifiesta tanto en su propio autoerotismo como en el vínculo dependiente que establece con la cocaína y la traducción. Rímini se transforma en un adicto a los rituales del placer que se reiteran en su cotidianeidad. La aparición de Verá marca un fuerte redescubrimiento corporal de Rímini que se traduce en el casi obsesivo vínculo que establece con la masturbación. Así, parece recobrar el ímpetu juvenil que lo conduce a experimentar con las posibilidades de su piel:

A las cuatro de la tarde empezaba a masturbarse -máximo cuatro y media. Iba al baño y, de pie ante el inodoro, posición que elegía por comodidad, para no tener luego que preocuparse de limpiar el semen, y también por el parentesco que reconocía entre el semen y otras excrecencias humanas, se apoyaba contra la pared, forcejeaba con la pija, con ese pescado inerte que hubiera dado todo por poder llamar pija, y después de un rato, desalentado, volvía al escritorio, miraba otra vez el reloj, y rastreaba en la biblioteca una edición de bolsillo de Las once mil vergas (Pauls, 2003: 105). 
Al igual que buena parte de El pasado, la narración de la disipada vida de Rímini con Vera incluye una alusión intertextual que complementa la lectura de la novela ${ }^{1}$. El traductor argentino se estimula con la lectura de uno de los clásicos de la literatura pornográfica escrito por Guillaume Apollinaire (2008). Las once mil vergas pueden situarse en la línea del Marqués de Sade puesto que el libro está marcado por una abierta y desprejuiciada exploración sexual, incluyendo episodios de sodomía, sadismo, necrofilia, entre muchos otros. Por lo demás, una sección de la crítica ha considerado que el texto tiene una marcada inclinación homosexual al considerar que Mony, el príncipe Vibescu, es sodomizado por diversos personajes: el vicecónsul de Serbia, Bandi Fornoski, su ayuda de cámara, Cornaboeux, su masajista, entre otros personajes, mantienen relaciones homoeróticas con el príncipe Vibescu. La alusión a Las once mil vergas no es azarosa debido a que permite entender la apertura de Rímini a una experiencia homosexual con un cantante argentino:

Sintió que le abrían el cierre del pantalón y que un animal femenino, tembloroso y húmedo, se inmiscuía y escarbaba en sus calzoncillos. "Qué pasa: cestá desanimada?", dijo el cantante, aniñando la voz. "Vamos a ver". Abrió la guantera. Un chorro de luz iluminó el interior del auto. Rímini bajo los ojos, se miró la verga, que yacía acobardada entre los dedos del cantante, y no pudo evitar mirarle las uñas limadas, brillantes, impecables. El cantante despejó la guantera de casetes hasta dar con un papel de cocaína que se agazapaba en el fondo. Lo abrió con rapidez, con una sola mano, y volcó lo poco que quedaba de droga en el grande de Rímini: "Ahora resucita, vas a ver". Le estuvo lamiendo un rato, se la frotó contra las encías y por fin se metió la verga entera en la boca (Pauls, 2003: 138).

La experiencia homoerótica de Rímini se ve truncada porque tiene tal cantidad de cocaína en su cuerpo que le es imposible lograr una erección.

${ }^{1}$ Alan Pauls establece diversas conexiones con textos capitales del canon occidental, entre los que destacan La divina comedia de Dante Alighieri y En busca del tiempo perdido de Marcel Proust. En este punto son útiles los trabajos de Elena Donato: "La traducción como invención de contemporaneidad. Sobre El pasado de Alan Pauls" (2005) y "Marcel Proust y Alan Pauls: correspondencias en El pasado" (2009). Asimismo, establece vínculos con cintas tales como Torrentes de amor (1984) de John Cassavetes y La historia de Adela H. (1975) de François Truffaut. 
Como sea, el episodio pone en evidencia la extrema intensidad con que enfrenta las experiencias vitales en el período de Vera, período en el que el ascendente consumo de cocaína juega un rol central: "Cuando fraccionaba, tomaba la primera raya y, aunque insatisfecho, porque sus ganas de inhalar siempre eran inversamente proporcionales a la cantidad de droga que iba quedando en el retrato" (Pauls, 2003: 111). Así, la adicción al alcaloide lo lleva a perder el control. De ahí que, por ejemplo, en una fiesta le dé una paliza a un antiguo amigo de Sofía sin ningún motivo aparente. Todo lo anterior se ve cruzado por la extrema obsesión con la que enfrenta la traducción de textos. Rímini se convierte en un obseso de un trabajo que lo aprisiona y lo envuelve hasta el punto de aislarlo del mundo externo: "La droga, la verdadera droga, era traducir: la verdadera sujeción, el anhelo, la promesa" (Pauls, 2003: 106).

El onanismo, el consumo de cocaína y la traducción se conjugan para generar uno de los períodos más exaltados de la vida de Rímini. Lo anterior se ve coronado por las visitas nocturnas que le realiza Vera y, ciertamente, por el placer que significa y representa el cuerpo de Vera. En este sentido, el capítulo de Vera puede ser entendido a partir de la relectura del concepto de "pulsión de muerte" propuesta por Slavoj Žižek en Visión de paralaje. Žižek contraviene la interpretación tradicional efectuada sobre el concepto propuesto por Sigmund Freud. Para el filósofo esloveno, la "pulsión de muerte" no consiste en un anhelo de destrucción o autoaniquilación que implica el "[...] retorno a la ausencia inorgánica de cualquier tensión vital" (2006: 104), lo que, en su perspectiva, corresponde al "principio de nirvana”. Así, Žižek pone en movimiento una inversión jerárquica de la "pulsión de muerte", debido a que este concepto consiste en una oposición a la muerte que produce sujetos poseídos por un "siniestro exceso de vida" (2006: 105). Para Žižek la "pulsión de muerte" se relaciona con la búsqueda de un exceso que no soporta y que desprecia el curso ordinario de las cosas. Žižek sostiene que la pulsión de muerte freudiana es -a pesar de que su nombre se lo da su contrario- la búsqueda de la superabundancia de vida: "La lección definitiva del psicoanálisis es que la vida humana nunca es "solo vida": los humanos no estamos simplemente vivos, estamos poseídos por la extraña pulsión a disfrutar de la vida en exceso, apegados apasionadamente a un exceso que no soporta y que desprecia el curso ordinario de las cosas" (2006: 105). 
La "pulsión de muerte" explica, entonces, la extrema forma de vida que Rímini adopta en compañía de Vera. Las drogas, el sexo desenfrenado, la traducción compulsiva evidencian un anhelo de vértigo que conduce a la destrucción momentánea de su estabilidad de la percepción y, en consecuencia, de la mayor amenaza que cree estar experimentando el traductor argentino: la memoria.

Otoño. Hacia el final de su pasión por Vera, Rímini retoma el contacto con una antigua compañera de universidad, Carmen, con la que inicia un raudo romance que abre un compás erótico más cadencioso y sutil debido a que la inclusión de cariño tempera el ardor sexual. Luego de varias jornadas dedicadas a la traducción de un destacado conferencista extranjero, detona, entre ambos, el encuentro afectuoso:

Rímini entendió: llevaba cinco días enamorándose de Carmen, y la certeza de que sólo la necedad o el terror explicaban que no se hubiera dado cuenta incrementó la velocidad con que el dulce veneno se distribuía en su sangre [...] Todo amor tiene un instante inaugural, su big bang privado, pero que es por definición un comienzo perdido, del que los amantes, por perspicaces que sean, nunca son contemporáneos (Pauls, 2003: 208).

Más que la cristalización del sentimiento amoroso, sentimiento que está muy lejos de la intensidad de la conexión con Sofía, el noviazgo, primero y el matrimonio, después, con Carmen, puede interpretarse a partir de la noción de ternura de Roland Barthes. Para Barthes, la ternura consiste en la irrupción de una "bondad mutua": "[...] nos materializamos mutuamente, volvemos a la raíz de toda relación, allí donde necesidad y deseo se juntan. El gesto tierno dice: pídeme lo que sea que pueda aplacar tu cuerpo, pero tampoco olvides que te deseo un poco, ligeramente, sin querer tomar nada enseguida" (Barthes, 1993: 182). La introducción de la ternura en la vida de Rímini, la que incluso lo lleva a contraer matrimonio con Carmen, determina un sensible decaimiento del goce erótico, el que si bien no desaparece, se ajusta a una exploración erótica más sosegada:

Pero tenía a Carmen, tesoro impagable; tenía sus dosis justas de pasión, de levedad y de temple, su compulsión a empequeñecer todo lo que amaba, su extraña, sonriente manera de abrirse paso en el mundo llevándolo siempre de la mano, no como si lo ayudara, sino más bien 
dando a entender, y haciéndoselo creer, que él, Rímini, era la verdadera fuerza motriz y ella sólo la encarnación material del movimiento (Pauls, 2003: 239, cursivas mías).

De esta forma, me interesa subrayar la calificación que el narrador le da al erotismo de Carmen y Rímini, “dosis justas de pasión”, lo que difiere de la extrema búsqueda del placer en el período que comparte con Vera. La dosificación del placer excluye la "sangre" y la "pasión" que pudiera distorsionar la "ternura" que comparten los traductores argentinos, tal como evidencia, por ejemplo, la sesión de sexo nocturno que tienen en Brasil:

[...] y Rímini sintió el roce de los dedos contra su pecho y se estremeció, y oyó que Carmen, riéndose, decía "mn, que recibimiento tan entusiasta”, y cuando sintió que ella se le sentaba encima y empezaba a acomodarse, apretó los párpados y se hundió en una negrura densa, sin fondo [...] le parecía que acababa de quedar embarazada (Pauls, 2003: 255).

Carmen queda, efectivamente, embarazada en ese viaje, lo que templa aún más la vida sexual de ambos. La llegada de Lucio, el hijo de la pareja, viene a cristalizar un vínculo desligado de la pasión y que, en este sentido, se parece mucho más a la relación que Rímini tuvo con Sofía. Ahora bien, el secuestro de Lucio - perpetrado por Sofía- gatilla el fin del matrimonio con Carmen y el derrumbe de Rímini, derrumbe que lo lleva a un estado de decadencia física y moral.

Verano. Tan solo la providencial aparición de un amigo de su padre, quien lo incentiva a regresar a una de sus antiguas pasiones, el tenis, le permite a Rímini reinventarse y retomar una cierta voluntad de vivir. Precisamente, su retorno al tenis como entrenador lo pone en contacto con una mujer con la que mantiene un escaso vínculo afectivo pero con la que lo liga un intenso ardor en la ejecución de los placeres de la carne, Nancy -mujer rica, de edad madura, que experimenta las constantes ausencias de su esposo- se erige como una verdadera ninfómana que se abre a las más variadas posibilidades del eros. De hecho, un antiguo entrenador del club le cuenta a Rímini de las constantes performance sexuales que experimentó con la neófita tenista:

Nancy en las duchas, enjabonada, la cara estampada contra los azule- 
jos; Nancy, con el grip de su nueva raqueta de grafito entre las piernas; Nancy en cuatro patas, con la vincha de toalla entre los dientes; Nancy contra el ligustro; Nancy colgada en las barras paralelas del gimnasio; Nancy con la boca llena; Nancy salpicada (Pauls, 2003: 429).

La relación de Nancy y Rímini puede ser leída a partir de lo que Georges Bataille denomina como "La carne", al establecer una semejanza entre la ejecución del eros y el sacrificio, dado que ambos revelan "la convulsión ciega de los órganos":

[...] libera unos órganos pletóricos cuyos juegos se realizan a ciegas, más allá de la voluntad reflexiva de los amantes. A esa voluntad reflexiva la suceden los movimientos animales de esos órganos hinchados de sangre. Una violencia, que la razón deja de controlar, anima a esos órganos, los hace tender al estallido y súbitamente estalla la alegría de los corazones al dejarse llevar por el rebalsamiento de esa tormenta. El movimiento de la carne excede un límite en ausencia de la voluntad. La carne es en nosotros ese exceso que se opone a la ley de la decencia (Bataille, 1997: 97-98).

La construcción del episodio de Nancy responde a la imaginería pornográfica masculina, en términos de que la tenista aparece representada como una mujer poseída por el sexo, "[...] empujada por un impulso irresistible a arrojarse sobre el pene masculino, es decir, tal como los hombres, en su fantasía, se comportan frente a ellas" (Alberoni, 2006: 17-18). Francesco Alberoni subraya, en este sentido, que en este universo imaginario: "[...] no hay cabida para ningún otro sentimiento, para ninguna otra relación. La imaginación erótica masculina pura se desembaraza de todo aquello que la entorpece" (2006: 19). Alberoni explicita la manera de operar de la imaginería pornográfica masculina analizando la propuesta literaria de Henry Miller:

De la mujer sólo interesa el sexo, nada más. Si Miller agrega algún detalle es intelectual, es voraz, es tímida, es reservada -se refiere siempre al sexo. Tampoco describe el cuerpo. No nos dice si es morena, rubia o pecosa. Lo único que menciona es la raza: por lo general, judía o negra, y también su comportamiento durante el acto sexual: ávido, desenfrenado. También para Miller todas las mujeres se nos brindan [...] es el encuentro del macho con la perra en celo (2006: 19). 
A todas luces, la ausencia de voluntad de los amantes, la búsqueda de esa libertad amenazante y, sobre todo, la representación de una imaginería pornográfica masculina aparecen representadas en el vínculo del traductor y Nancy:

Nancy ensayó una resistencia perezosa, tan teatral como sus rastros de resaca, y después cedió y se aflojó y casi se desmaya en sus brazos [...] Rímini la levantó contra la pared, tiró al piso unos cuadros y fue ubicándola con una rara, maniática precisión, hasta que dio con la altura que buscaba, y después de quedarse quieto un segundo la penetró con una única, larga, lenta estocada. Nancy, como muerta, se dejó hacer [...] Se la cogió con la paciencia y la dedicación de un orfebre, las mismas que había invertido a lo largo de los últimos meses en ser su sombra y protegerla del mundo. Se la cogió con exhaustividad, con un sentido demente del detalle, atento a las menores señales que encontraba mientras exploraba el interior de su cuerpo, como un rastreador. Se la cogió para que nunca lo olvidara, para hacerla su esclava. Y cuando pegó una serie de corcoveos y acabó, a años luz de ella, que se roía las cutículas con los ojos clavados en las molduras del cielorraso, Rímini se hizo a un lado pero la mantuvo enlazada con un brazo, muy consciente, en su papel de amante profesional, del alivio que le proporcionaría al liberarla de su peso, pero también del desamparo que experimentan las mujeres después del sexo, cuando la satisfacción devuelve los cuerpos a la soledad (Pauls, 2003: 470).

Alan Pauls le da un tratamiento pornográfico al vínculo de Rímini y Nancy que se asocia con lo que el propio escritor argentino considera como una "[...] especie de estereofonía sobrenatural" (Pauls, 2003: 367) que eleva, permanentemente, la intensidad del fenómeno erótico. El autor de $E l$ pasado reconoce, en esta línea, que la seducción que le provoca la imagen pornográfica es muy superior a la que le motiva la imagen erótica:

Me interesa mucho esa experiencia en la que se alcanza como una especie de tope, la literalidad es una cosa por un lado muy básica como si hubiera una especie de sentido que no llegara a despegar y al mismo tiempo es un límite, haber llegado muy lejos [...] Hay una especie de descarnamiento del lenguaje que me parece más atractivo que ese juego de velos o secretos y escondites que plantea la imagen erótica (Kasztelan, 2009). 
La narración del primer encuentro erótico entre Nancy y Rímini deja en claro las preferencias estéticas del escritor argentino:

Nancy lo apartó y rápidamente ocupó su lugar; se recostó boca abajo sobre la mesa, tironeó de su bombacha, liberando la entrada de su sexo, y luego, aferrándose a los bordes de la mesa con las manos, como un náufrago en una balsa, empezó a temblar y a sacudirse, golpeando con el pecho la superficie de madera. “Ahora”, gimió entre dientes, "adentro, ya, metémela”. Rímini se acercó y se apoyó tímidamente sobre sus nalgas, y Nancy se frotó contra él, buscando una dureza que no encontró, y fuera de sí se puso a tantear las bolsas de compras que yacían en el piso, alrededor de la mesa. “Algo, hijo de puta”, gritó, mientras su mano palpaba el aire desesperada, "lléname la concha ya o te mato, hijo de remilputas". [...] Se agachó, metió una mano entre las bolsas, sacó una botella al azar - ananá fizz- y embutió el cuello completo, con el corcho, el alambre y el forro del papel dorado, en el sexo de Nancy. La oyó lanzar un gemido largo, de placer y de asombro; sintió como se contraía en un espasmo, electrizada por el cuerpo extraño que acababa de interrumpir en ella, y luego, en parte quizá para evitar el dolor, en parte para hacer durar el deleite, cómo empezaba a moverse con extremada lentitud, tragando y devolviendo la botella rítmicamente. Rímini se quedó quieto, ligeramente inclinado sobre el cuerpo de Nancy, sujetando la base de la botella con una mano firme [...] Rímini aprovechó que Nancy, tentada por el contacto accidental entre su pubis y el borde de la mesa, se desprendía momentáneamente de la botella, y se colocó tras ella y espero que volviera, de modo que, después de frotarse con furia, cuando retrocedió para buscarla de nuevo, lo que Nancy se hundió entre las piernas no fue el cuello del envase sino la carne palpitante de Rímini (Pauls, 2003: 368).

No se puede soslayar que la historia de Nancy pone en evidencia la predilección de Pauls por construir mímesis heterogéneas. Lo anterior tiene que ver con la combinación de una prosa elegante y obscena que genera atractivas ondulaciones en la representación de la realidad de la novela: “[...] me interesa mucho el efecto de obscenidad, de abyección que produce una incrustación porno en medio de una prosa elegante y elevada. Me gustan mucho esas caídas de la prosa. Y eso también me gusta hacerlo con el mal hablar o con la injuria. Me gustan las pérdidas de altura" (Kasztelan, 2009). El descenso a un plano obsceno de El pasado subraya, a todas luces, el carácter pornográfico que adquiere la conexión de Rímini y Nancy. 
Al margen del amor y de la ternura del vínculo con Sofía o Carmen, respectivamente, Rímini solo halla en Nancy la carne húmeda y trémula que le permite experimentar el desenfreno erótico. En este sentido, Pauls opera a partir de la "pulsión de muerte" que se había apoderado de Rímini en la etapa con Vera en cuanto a la intensidad de vida. No se puede pasar por alto, sin embargo, que se trata de la persecución de un límite exclusivamente en el ámbito sexual, dado que Rímini se ha librado de las obsesiones que tenía por la traducción y, sobre todo, por la cocaína. Bajo esta perspectiva, es posible asociar el tratamiento que Pauls le da a esta sección del libro con lo que Deleuze denomina como literatura pornológica, es decir, una literatura que permite situar el lenguaje en conexión con su propio límite, con una suerte de "no lenguaje", que emplea violentas formas de representación del erotismo, construyendo, en definitiva, una erótica que se relaciona tanto con la búsqueda de una exuberancia que deslegitima el curso ordinario de las cosas y que, en consecuencia, apunta a gozar de la vida hasta el extremo, como con la posibilidad de llevar la representación erótica hasta lograr un efecto de obscenidad que desplaza al lenguaje hasta su última frontera.

\section{Último movimiento}

El tratamiento del erotismo en El pasado está vinculado con el amor. Transgrediendo la teoría de La llama doble de Octavio Paz, Pauls construye una relación inversamente proporcional entre amor y el erotismo, es decir, entre mayor sea la presencia de eros menor es la presencia del amor y viceversa. Así lo prueban los cuatro movimientos que componen la "sinfonía erótica" de la novela, los que están asociados a las figuras de las cuatro mujeres que marcan la vida de Rímini: Sofía, Vera, Carmen y Nancy. Si Sofía viene a representar la máxima idealización del amor y la mínima presencia del erotismo, Nancy encarna la mínima presencia del cariño y la máxima efervescencia de la carne.

Los diversos modos de la "sinfonía erótica" están vinculados con la utilización del lenguaje. Si el amor o la ternura son tratados con una prosa elegante, pulcra, elevada, el "erotismo ardiente" es abordado a través de un descarnamiento del lenguaje que conduce a una caída o incluso a un 
derrumbe de la prosa que sucumbe al mal hablar, la injuria y la imprecisión lingüística.

En consecuencia, a diferencia de otros textos hispanoamericanos contemporáneos que abordan, ampliamente, el erotismo, como Los detectives salvajes de Bolaño o Vivir afuera de Fogwill, los que trabajan en una misma tonalidad e intensidad los movimientos y rituales del eros, Pauls emplea diversas intensidades y matices en los modos de representación de los juegos de la piel, desplazándose desde la ternura hacia la violencia extrema y la crueldad.

Las nociones de "sinfonía erótica", "amor siniestro" y "geología del amor" dialogan estrechamente, tanto porque mientras la primera contribuye a entender la presencia del erotismo, las dos últimas facilitan la interpretación del amor en El pasado. Ahora bien, los alcances de la triada de conceptos son disímiles. Mientras el "amor siniestro" y la "geología del amor" tienen una función restringida en cuanto solo se pueden aplicar al vínculo amoroso de Sofía y Rímini, es decir, la pareja protagónica de $E l$ pasado, la "sinfonía erótica" consiente una lectura trasversal al permitir el análisis del conjunto de relaciones erótico-sentimentales presentes en la novela.

Así, estamos frente a una novela que intenta hacerse cargo de la multiplicidad de significados y representaciones que tiene el fenómeno erótico en la Argentina de las últimas décadas. Bajo esta perspectiva, es posible sostener que Pauls asume el desafío impuesto por Cortázar cuando éste establece que una de las grandes batallas que libra es por la liberación erótica. El llamado de Cortázar tuvo una recepción importante en la narrativa argentina de las década de 1960 y 1970. Martina López establece que la literatura trasandina de esas décadas tiene como elemento común la voluntad de irritar y provocar a partir de la narración de los cuerpos, lo que supone "[...] volverlos protagonistas del relato y construir el conflicto en la confrontación que establecen" (2000: 183). Nanina de Germán Leopoldo García, El fiord de Osvaldo Lamborghini, El frasquito de Luis Guzmán y La boca de la ballena de Héctor Lastra se pueden situar como parte de una producción narrativa orientada a escribir los cuerpos. Para López, estas novelas dan cuenta de un erotismo que implica un cruce con el poder: "El cuerpo propio y el ajeno están allí marcando límites o invitando a borrarlos, posibilitando encuentros o fusiones, imponiendo necesidades, abriendo o 
clausurando los deseos" (López, 2000: 183). A partir de la década de 1980, la narrativa argentina comienza a incorporar nuevas miradas sobre el fenómeno erótico. Así, se abre hacia la perspectiva femenina con textos tales como La rompiente de Reina Roffé y Canon de alcoba de Tununa Mercado, las que incorporan "[...] la dimensión del placer donde el autoconocimiento femenino está en juego y es en todo caso en él donde late una perspectiva política" (López, 2000: 183). A ello habría que agregar la inclusión de nuevas voces que narran el universo homosexual.

En este escenario de apertura erótica es necesario situar a El pasado. Pauls no solo prosigue la batalla desplegada por Cortázar y por la serie de escritores que asumieron su llamado, sino que llega mucho más lejos en la liberalización erótica, la transgresión de los tabúes y en la combinación cuerpo e inteligencia de lo planteado por el autor de Rayuela.

La "sinfonía erótica" de Alan Pauls en El pasado genera, en definitiva, una amplia e intensa reconstrucción de los rostros del erotismo en la nación trasandina de fin de siglo, reconstruyendo a través de diversas imágenes y recursos textuales una de las temáticas ineludibles de la literatura occidental: las mil formas de amar. Y de gozar.

\section{Referencias}

Alberoni, F. (2006). El erotismo. Barcelona: Editorial Gedisa.

Aliaga, A. (2006). Mutaciones de la postpasión y el arte enfermo en El pasado de Alan Pauls. Tesis de Magíster en Letras con mención en Literatura. Pontificia Universidad Católica de Chile.

Apollinaire, G. (2008). Las once mil vergas. Madrid: Valdemar.

Barthes, R. (1993). Fragmentos de un discurso amoroso. México DF: Siglo Veintiuno Editores.

Bataille, G. (1997). El erotismo. Barcelona: Tusquets editores.

Candia Cáceres, A. (2014). La geología siniestra del amor en El pasado de Alan Pauls. Literatura y Lingüística, 30, 49-72.

Deleuze, G. (1989). Coldness and cruelty. En L. Sacher-Masoch, Masochism (pp. 9-69). New York: Zone Brooks.

Donato, E. (2005). La traducción como invención de contemporaneidad. Sobre El Pasado de Alan Pauls. Boletín del Centro de Estudios de Teoría y Crítica Literaria, 12, 1-14. . (2009). Marcel Proust y Alan Pauls: correspondencias en El pasado. Fragmentos, 37, 27-37. 
Echevarría, I. (2007). Desvíos. Un recorrido crítico por la reciente narrativa latinoamericana. Santiago: Universidad Diego Portales.

Encuentros digitales. (2004). Alan Pauls. Disponible en http://www.elmundo. es/encuentros/invitados/2004/03/991/

Goic, C. (2000). Capítulos de la Historia de la Novela Hispanoamericana: Vargas Llosa, Del Paso, Giardinelli. En L. Sáez Godoy (ed.), Literatura y Lingüística (pp. 99-112). Valparaíso: Universidad de Playa Ancha Editorial.

Han, B. C. (2014). La agonía del Eros. Barcelona: Herder.

Kasztelan, N. (2009). 39 preguntas a Alan Pauls. Disponible en http://www. no-retornable.com.ar/v3/entrevista/

López, M. (2000). La narración de los cuerpos. En E. Drucaroff (ed.), Historia crítica de la Literatura Argentina Volumen 11. La narración gana la partida (pp. 183-215). Buenos Aires: Emecé Editores.

Pauls, A. (2003). El pasado. Barcelona: Anagrama.

Paz, O. (1994). La llama doble. Amor y erotismo. México: Editorial Seix Barral. Žižek, S. (2006). Visión de Paralaje. Buenos Aires: Fondo de Cultura Económica. 